\title{
Taxonomy comes of age
}

\author{
Naming Nature: The Clash Between Instinct \\ and Science \\ by Carol Kaesuk Yoon \\ W. W. Norton: 2009. 352 pp. $€ 19.99 / \$ 27.95$
}

Faced with the bewildering diversity of nature, humans have long attempted to classify it. In her personal and readable perspective on taxonomy, Carol Yoon argues that the basic instinct to recognize natural groups has gradually been replaced by an increased rationality.

Yoon explores the formative environment, motives and personality of the field and scientists within it, from its origins to maturity. She argues that taxonomy generates new views of the world that are counterintuitive, for example that fungi are more like animals than plants; reductionist, depending on molecular data and statistical techniques; and bewildering, such as the prolific yet invisible domains of bacteria and archaea. She is concerned that the professionalization of biology has distanced humanity from nature. But her incursions into anthropology, neuroscience and psychology to explain our empathy with nature are disappointingly superficial.

The first major step in taxonomy was taken by Carl Linneaus some 250 years ago. In a magnificent work, Systema Naturae, he ordered the known natural world. Although the places of some organisms in his scheme have changed, his binomial system for naming organisms has stood the test of time.

A century later, in 1859, came Darwin's theory of evolution, with its seismic impact on science and society. Surprisingly, its effect on taxonomy was minimal. Taxonomists continued for another century to explore the world and discover new species as before, now drawing tree diagrams to represent the relationships between organisms and their evolution. Some of these evolutionary trees were insightful, others fanciful. Unfortunately none was testable, repeatable or objective. So taxonomy got a bad name.

Yoon rightly recognizes the role of the 1960s movement of quantitative experimentalists in being the most significant first step in transforming the field into a full science. These numerical taxonomists started a serious debate on how to articulate earlier opinions and experience, and distil them into testable conclusions. As a result, data and transparent methodology came to challenge 'expert' opinion. However, these researchers treated all data equally, without considering their relative evolutionary or biological significance.

A more rational and evolution-based approach was needed. For some this was found in DNA sequences. But this approach attracted a similar criticism, namely that a complex organism couldn't be reduced to a string of nucleotides.
Over the following period of great change in biology and computational technology, taxonomists struggled to find their way. In the 1970s, the phylogenetics movement arose with a simple message: to seek close relatives with similarities that are shared uniquely by their descendants and no other groups. With this powerful new methodological tool came fervent disciples, called 'cladists', who wanted to purge the field of non-adherents. Taxonomy again turned in on itself, ignoring the huge strides being made in areas such as developmental genetics, population genetics and population biology that could have crucially informed their interpretations of nature. Describing these ideological waves, Yoon's book comes alive with her tales of meeting influential figures, including the God-like Ernst Mayr.

Yoon leaves us with taxonomy having passed though its rebellious adolescence into maturity. But what of its future? Taxonomy has never had so many tools at its disposal and so many connections to the rest of biology. The tragedy is that there are too few taxonomists who can utilize these advances and tackle the challenging questions of our time.

Richard Lane is director of science at the Natural History Museum, London SW7 5BD, UK, and author of the recent report Taxonomy in Europe in the 21st Century.

e-mail: r.lane@nhm.ac.uk

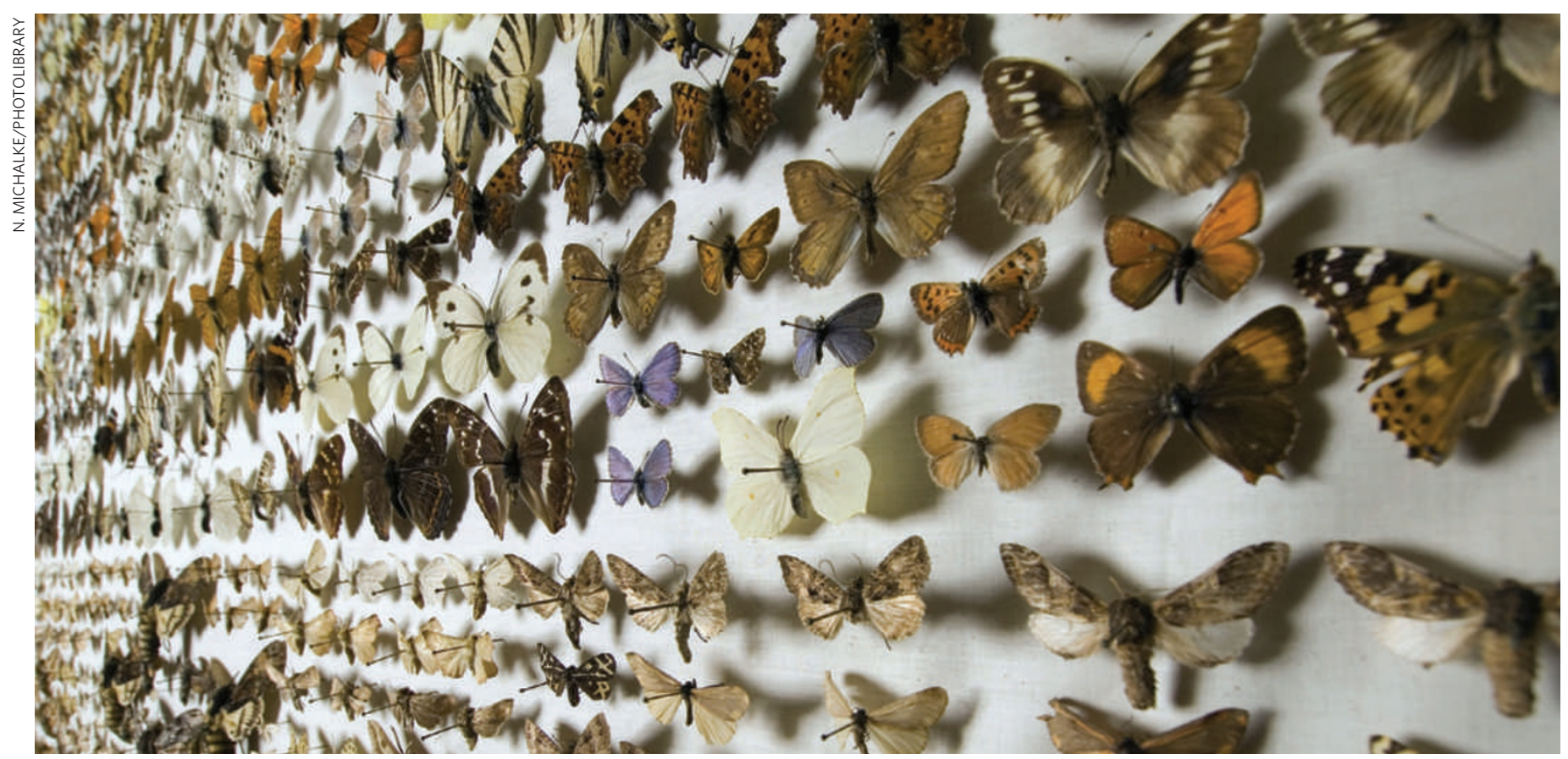

Collections such as this at Berlin's Museum of Natural History may inspire taxonomists of the future. 